\title{
The clinical picture of ectasia of the intracerebral arteries
}

\author{
YL YU, IF MOSELEY, P PULliCiNO, WI MCDONALD \\ From the Lysholm Radiological Department and the University Department of Clinical Neurology, The \\ National Hospital, London
}

SUMMARY Thirty-one patients with ectasia of intracranial arteries were studied. The carotid system was more frequently involved than the vertebrobasilar. The condition is relatively rare and usually occurs with other vascular disease. Ectasia presents with a variety of neurological symptoms, amongst which visual disorders are common. The overall mortality was $52 \%$, but the prognosis was appreciably worse for the vertebrobasilar group, probably because of a higher incidence of compression of surrounding neural structures. Defects in the internal elastic lamina, with or without associated atheroma, are often found in the affected arteries.

Ectasia, or pathological enlargement of the cerebral arteries is a rare, though well recognised finding at cerebral angiography. Several series of vertebrobasilar ectasia, ${ }^{1-4}$ and one of carotid ectasia ${ }^{5}$ have previously been published, but there has not been a comprehensive account of the symptomatology and the natural history of this condition. We have therefore, reviewed the experience of ectasia of cerebral arteries in the National Hospitals over the past 22 years.

\section{Material and methods}

Of the approximately 40000 carotid and 10000 vertebral angiograms performed at the National Hospital, Queen Square between 1959 and 1980, films of those reported as showing dilatation and tortuosity of vessels were reviewed. Measurements were made of the diameter (corrected for magnification) of the major vessels as demonstrated by cerebral angiography. In addition, the course of the ectatic basilar and vertebral arteries was noted, as were the relationships of the internal carotid arteries and the termination of the basilar arteries in the sella and suprasellar regions. Thirty-two normal carotid and 18 normal vertebral angiograms of an age-matched group of patients were also examined. Ectasia was diagnosed when the diameter of the vessels was greater than normal along all or part of their course, and when they were also abnormally tortuous. Whereas the former was determined by measurement, the latter feature was

Address for reprint requests: Professor WI McDonald, University Department of Clinical Neurology, The National Hospital, Queen Square, London WCIN 3BG, UK.

Received 29 August 1981

Accepted 26 September 1981 assessed by eye. Twenty-nine cases showed unequivocal arterial ectasia and to this number we have added two cases seen at the Maida Vale Hospital in the past four years. Of the 31 cases, the carotid tree was affected in 14 , the vertebrobasilar system in eight and both in nine. Four of these cases had been reported by Moseley and Holland. ${ }^{4}$ The clinical records of these patients were then reviewed and the subsequent course of the majority assessed: either by personal examination (11 cases), or from hospital records, necropsy reports, death certificates and reports from family doctors (17 cases). Follow-up data were not available in the remaining three patients.

\section{Results}

SEX AND AGE (TABLE 1)

Three-quarters of the patients were male (26 of 31 ). The age of presentation ranged from 43-73 years; 23 patients $(72 \%)$ were in the 6 th and 7 th decades. Women tended to present at a later age than men.

Table 1 Sex and age distribution

\begin{tabular}{lcc}
\hline $\begin{array}{l}\text { Age at } \\
\text { presentation }(y r)\end{array}$ & Male & Female \\
\hline $41-50$ & 6 & 0 \\
$51-60$ & 8 & 1 \\
$61-70$ & 11 & 3 \\
$71-80$ & 1 & 1 \\
Total & 26 & 5 \\
\hline
\end{tabular}

ASSOCIATED ABNORMALITIES

Hypertension There were 20 patients $(64 \%)$ in whom the diastolic blood pressure consistently exceeded $100 \mathrm{~mm} \mathrm{Hg}$. In the majority the elevation was mild or moderate, but two had malignant 
hypertension. Twelve patients had been known to be hypertensive for periods ranging from six months to ten years, while raised blood pressure was discovered in six at the time of presentation and a further two were found to be hypertensive eight and eleven years later respectively.

Vascular disease Ischaemic heart disease was common, eleven patients $(35 \%)$ having clinical or electrocardiographic abnormalities or both. Peripheral vascular disease was present in three, one of whom subsequently required below-knee amputation. Only seven patients $(23 \%)$ gave a family history of vascular disease.

Diabetes mellitus Three patients had mild diabetes and two had abnormal glucose tolerance tests, none of whom required other than dietary control. A family history of diabetes was present in a further two cases.

Tobacco of the 27 patients for whom relevant information was available, $20(74 \%)$ were smokers, seven consuming more than 20 cigarettes per day.

Hyperlipidaemia Only one patient had hypercholesterolaemia, while three had elevated fasting triglyceride levels.

SYMPTOMS AND SIGNS AT PRESENTATION

(TABLE 2)

Carotid ectasia Of the 23 patients with carotid ectasia, $14(61 \%)$ presented with ischaemic episodes.

Table 2 Presenting features

\begin{tabular}{|c|c|c|c|}
\hline & $\begin{array}{l}\text { Carotid } \\
\text { ectasia }\end{array}$ & $\begin{array}{l}\text { Vertebrobasilar } \\
\text { ectasia }\end{array}$ & $\begin{array}{l}\text { Ectasia in } \\
\text { both } \\
\text { systems }\end{array}$ \\
\hline \multicolumn{4}{|l|}{ Cerebral ischaemia } \\
\hline $\begin{array}{l}\text { Hemisphere TIAs } \\
\text { Hemisphere } \\
\text { stroke }\end{array}$ & 1 & & 3 \\
\hline Epilepsy & 2 & & \\
\hline \multicolumn{4}{|l|}{ Retinal ischaemia } \\
\hline (acute) & 3 & & \\
\hline \multicolumn{4}{|l|}{ Optic nerve lesion } \\
\hline Acute & 1 & & \\
\hline Insidious & 1 & & \\
\hline Acute III palsy & 1 & & \\
\hline Acute VI palsy & 1 & & \\
\hline \multicolumn{4}{|l|}{ Acute Horner's } \\
\hline $\begin{array}{l}\text { syndrome } \\
\text { Brain stem deficits }\end{array}$ & \multicolumn{2}{|c|}{ Brain stem deficits } & \\
\hline Acute & & 1 & 2 \\
\hline Insidious & & 1 & 2 \\
\hline Hydrocephalus & & 2 & \\
\hline \multicolumn{4}{|l|}{ Chiasmal } \\
\hline compression & & 1 & \\
\hline Trigeminal pain & & 1 & \\
\hline \multicolumn{4}{|l|}{ Subarachnoid } \\
\hline haemorrhage & 1 & & 2 \\
\hline Unrelated & 2 & 2 & \\
\hline
\end{tabular}

Thus, cerebral ischaemia occurred in six: three with hemisphere strokes, one with hemisphere transient ischaemic attacks, one with Jacksonian epilepsy and one with generalised epilepsy. Three patients presented with retinal ischaemia, one as amaurosis fugax and the others as infarction. Acute Horner's syndrome, third nerve palsy without pupillary involvement or sixth nerve palsy each occurred in one patient. Optic nerve lesions were present in two patients: the first had an acute optic neuropathy while the second showed progressive unilateral visual loss and optic atrophy, the mechanism of which could not be established with confidence; compression of the optic nerve by the ectatic carotid was not demonstrated but could not be excluded on the basis of the investigations performed. Three patients presented with subarachnoid haemorrhage, in only one of whom was a saccular aneurysm demonstrated. Hemisphere signs suggestive of ischaemia were also present in the other two. Ectasia in the carotid system was probably an incidental finding in six patients, four of whom presented with problems related to vertebrobasilar ectasia. Of the remaining two patients, one had a cerebral glioma and the other an asymptomatic pituitary adenoma.

Vertebrobasilar ectasia Eleven $(65 \%)$ of the 17 patients with vertebrobasilar ectasia had symptoms or signs related to the abnormal arteries.

Brain stem deficit was the commonest presentation $(6 / 17,35 \%)$, developing acutely in three cases and insidiously in another three. Examination revealed a variety of signs attributable to a lesion in the posterior fossa: cerebellar ataxia $(5 / 17,30 \%)$; pyramidal signs, Horner's syndrome each in two cases; nystagmus, gaze palsies each in three. Cranial nerve palsies occurred as follows: $V$ (two cases), VI (three cases), VII ( three cases), VIII (four cases), $\mathrm{X}$ (three cases), XI (one case), and XII (one case). One of these patients, with multiple posterior fossa signs, also had a left homonymous hemianopia and suffered from temporal lobe epilepsy. The last two features could have been contributed to by the observed indentation of the right temporal lobe by the rostral end of the ectatic basilar artery, but independent ischaemic lesions could not be excluded.

One patient had bitemporal hemianopia in association with compression of the optic chiasm by the ectatic basilar artery. Hydrocephalus secondary to third ventricular compression was the presenting feature in two patients, manifest in one as papilloedema and in the other as dementia, ataxia and dysarthria. Tic-like trigeminal pain was the sole manifestation in one patient. Another, who presented with a cerebral hemisphere stroke, was found to have brain stem signs, with impaired conjugate lateral gaze and ataxia. The two patients with carotid ectasia who presented with subarachnoid haemor- 
rhage without demonstrable aneurysms also had vertebrobasilar ectasia.

Vertebrobasilar ectasia was considered an incidental finding in five cases; one presented with chiasmal compression from an anterior communicating aneurysm, another with dementia presumed to be atherosclerotic in origin, and the remaining three with hemisphere strokes.

\section{PROGNOSIS}

Carotid ectasia Follow-up data were complete in 20 out of 23 patients, the review period ranging from 1 month to 17 years (mean 5.6 years). The mortality was $45 \%(9 / 20)$. Patients with ischaemic symptoms had a relatively benign course with appropriate treatment and only two in this group died.

Two patients with completed strokes and one with transient ischaemic episodes affecting the cerebral hemispheres had no recurrence over a period of 1 year, 4 years and $3 \frac{1}{2}$ years respectively; the first patient had undergone carotid endartectomy for carotid stenosis. Another patient with hemisphere stroke continued to improve slowly one month after presentation. The patient with Jacksonian epilepsy survived 10 years with occasional seizures, and died of pneumonia. The patient with generalised epilepsy was lost to follow-up.

Visual deficits in those with retinal and optic nerve ischaemia remained static, except for the patient with amaurosis fugax who became symptomfree after carotid endartectomy and anticoagulant therapy. The three patients with acute Horner's syndrome, IIIrd or VIth nerve palsies each made a good recovery, but the first subsequently developed symptoms of peripheral vascular disease requiring amputation of the left leg and also a right hemisphere stroke; he died of pneumonia 12 years after presentation.
Of the three patients with subarachnoid haemorrhage, one underwent carotid ligation for a posterior communicating artery aneurysm, but died six months later from recurrent haemorrhage. One of those without an aneurysm has had no recurrence of symptoms over a period of 12 years, while the other has had intermittent seizures with transient left hemipareses.

The patient with a cerebral tumour died ten years after presentation, but at no time had symptoms referable to arterial disease. The patient with an asymptomatic pituitary tumour died six months after presentation from a presumed cerebrovascular accident.

Vertebrobasilar ectasia Only one of the 17 patients in this group could not be traced. The follow-up period ranged from one month to ten years (mean 2.5 years) and the mortality was $63 \%(10 / 16)$. Two of the three patients with an insidious brain stem syndrome survived less than six months. The third survived for $4 \frac{1}{2}$ years with progressive deterioration. One of those presenting acutely died six weeks later from a ruptured aorta. The other two with acute brain stem deficits, presumed to be thromboembolic in nature, recovered fully with appropriate treatment-antihypertensive drugs in one and anticoagulants in the other. Both have led an active life for ten years.

Survival time in the cases of hydrocephalus was three months and one year respectively. In the latter case, a ventriculo-peritoneal shunt was inserted without benefit. The patient with chiasmal compression deteriorated steadily from an upper brain stem syndrome and died within ten months from pneumonia. The patient with trigeminal pain improved strikingly following thermocoagulation of the Gasserian ganglion.

The patients presenting with subarachnoid haemorrhage have already been described. Those

Table 3 Angiographic measurements in the control group

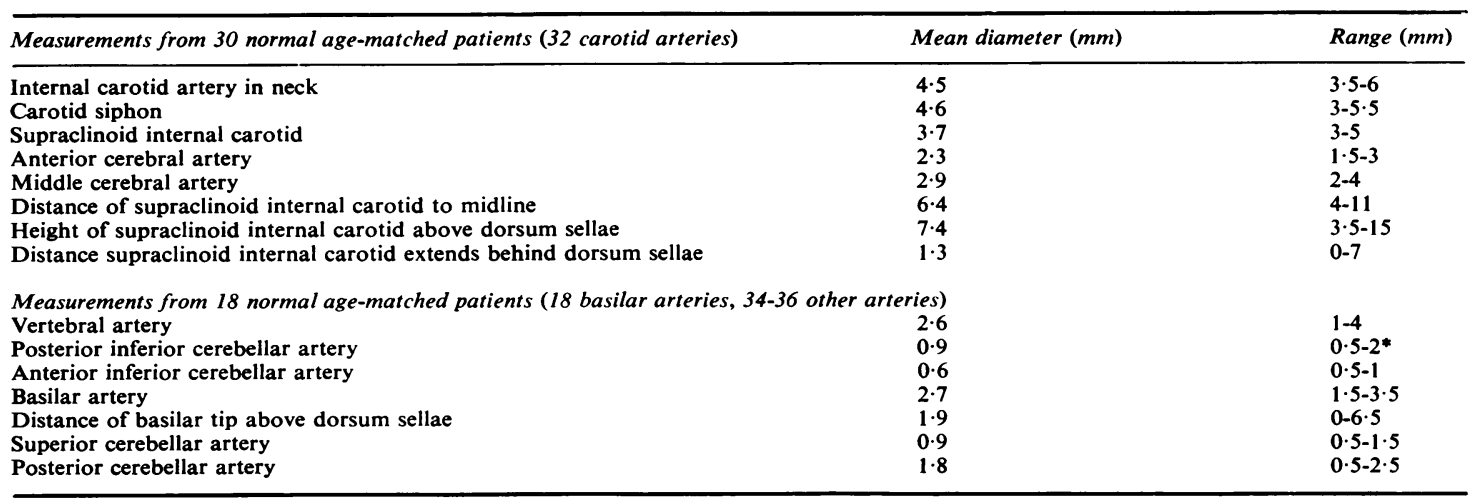

$0.5 \mathrm{~mm}$ was taken as minimum measurement for any visible artery. 

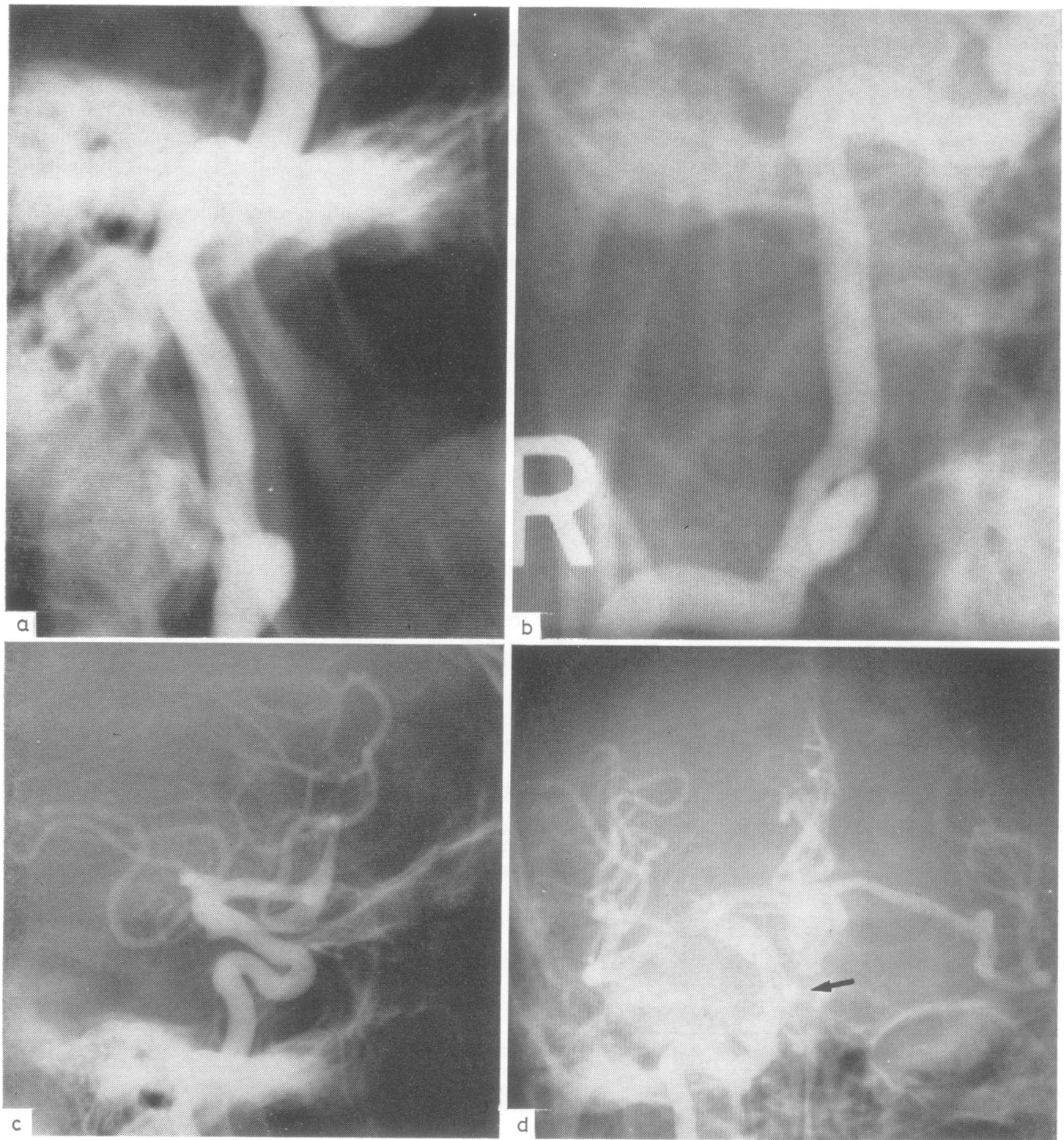

Fig 1 Carotid angiogram of a 54-year-old man presenting with an acute Horner's syndrome (a) lateral (b) AP views of the cervical internal carotid $(c)$ lateral and $(d)$ AP views of the intracranial vessels. A small outpouching, probably representing a local dissection, is seen in the cervical portion of the artery. There is a slight dilatation of the petrous and intracavernous segments of the internal carotid artery. The terminal portion is dilated (diameter $8 \mathrm{~mm}$ ), minimally curved and extends $18 \mathrm{~mm}$ above the dorsum sellae; it lies only $3 \mathrm{~mm}$ from the midline (arrow). The anterior and middle cerebral arteries are also ectatic.

with incidental vertebrobasilar ectasia had courses appropriate to their respective major medical problems. The patient with an anterior communicating aneurysm died one month later from subarachnoid

haemorrhage. The condition of the patient with presumed atherosclerotic dementia has remained unchanged over four years. Two patients with hemisphere strokes survived one year and four years 
respectively with no recurrence, and the third improved slowly one month after the acute episode.

\section{RADIOLOGICAL FINDINGS}

Measurements of the normal carotid and vertebral angiograms are presented in table 3.

Carotid ectasia Unilateral carotid angiograms were available for 18 patients and bilateral studies for five. Ectasia affected the extracranial internal carotid artery in 12 patients; in one of these-with an acute Horner's syndrome-the cervical portion of the artery showed an irregular focal dilatation, probably resulting from a small dissection (fig $1 \mathrm{a}$ and $\mathrm{b}$ ).

The entire carotid tree was involved in a minority of patients, but apart from a few cases in which the carotid siphons were normal, there was little variation in the luminal diameter of the intracavernous $(5 \cdot 5-8$, mean $6.8 \mathrm{~mm})$ and supraclinoid $(4-9$, mean $5.0 \mathrm{~mm})$ portions of the internal carotid arteries. The latter was slightly more dilated (mean $6.3 \mathrm{~mm}$ ) in the patients with coincidental ectasia. One of the patients who presented with posterior fossa signs had the most ectatic carotid branches.

The distances between the medial surface of the supraclinoid internal carotid artery and the midline averaged $6.0 \mathrm{~mm}$, that is, was within the normal range. There was no significant difference between the patients in whom the optic or ocular motor nerves were affected and those with hemisphere ischaemic lesions. The mean measurement in those patients in whom carotid ectasia was an incidental finding or associated with subarachnoid haemorrhage was $\mathbf{4 . 2} \mathrm{mm}$, indicating that demonstration of a medially lying ectatic artery is insufficient evidence that it is responsible for optic nerve compression.

The carotid siphons extended above and behind the dorsum sellae 5-19 (mean 12.0 mm) and 0-11 (mean $3.5 \mathrm{~mm}$ ) respectively. There was no correlation between these measurements and clinical presentation, and indeed most were within the normal range.

Ectasia affected the middle cerebral arteries in 12 cases (fig 1c and d). Five more were questionably abnormal. Only seven patients had ectatic anterior cerebral arteries, and again five were questionable. There were seven patients in whom all the major cerebral arteries demonstrated were definitely ectatic, and only four in whom all were normal. Marked irregularity of the intracranial branches was also present in four cases (fig 2).

Vertebrobasilar ectasia The tortuous course of the vessels brought them into close proximity to the affected structures, but there was little correlation between the size of the lumina of the vertebral and basilar arteries and the clinical presentation. The mean diameter of the basilar artery was $6.9 \mathrm{~mm}$ in patients with posterior fossa signs and $7.0 \mathrm{~mm}$ in
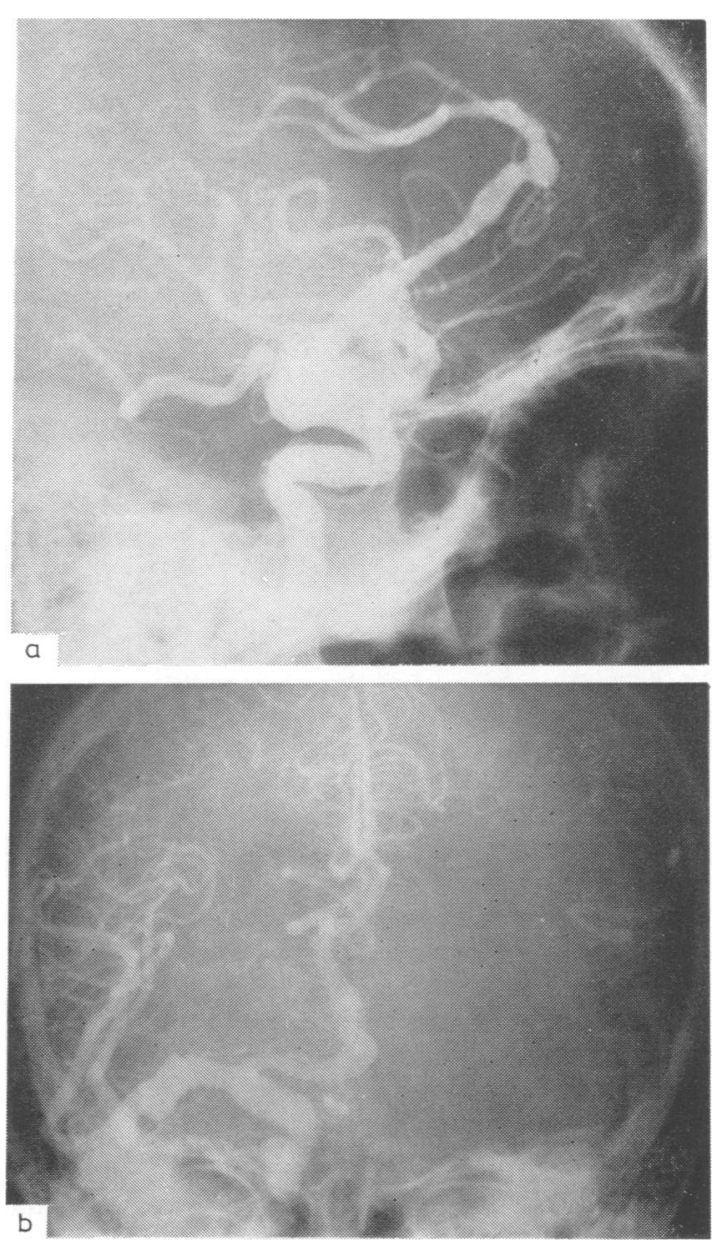

Fig 2 Carotid angiogram of a 55-year-old man presenting with an acute brain stem syndrome. (a) lateral (b) AP views. The extracranial and intracranial internal carotid artery is irregularly dilated (diameter 7-10 $\mathrm{mm}$ ), as are its terminal branches. The middle cerebral artery is $9 \mathrm{~mm}$ in diameter, the anterior cerebral artery $5 \mathrm{~mm}$.

those without. The artery was however larger in the former group presenting with hydrocephalus; the artery projected 23 and $27 \mathrm{~mm}$ above the dorsum.

The left vertebral artery was ectatic in every case, while the right was abnormal in six of the eight cases in which it was seen. Ectasia affected the branches as follows: posterior inferior cerebellar: left: $46 \%$; right: $30 \%$; superior cerebellar : left $25 \%$; right : $17 \%$ The posterior cerebral arteries were ectatic in $78 \%$, but the anterior inferior cerebellar arteries were normal. An example is shown in fig 3.

Pathological Findings Necropsy was carried out on 

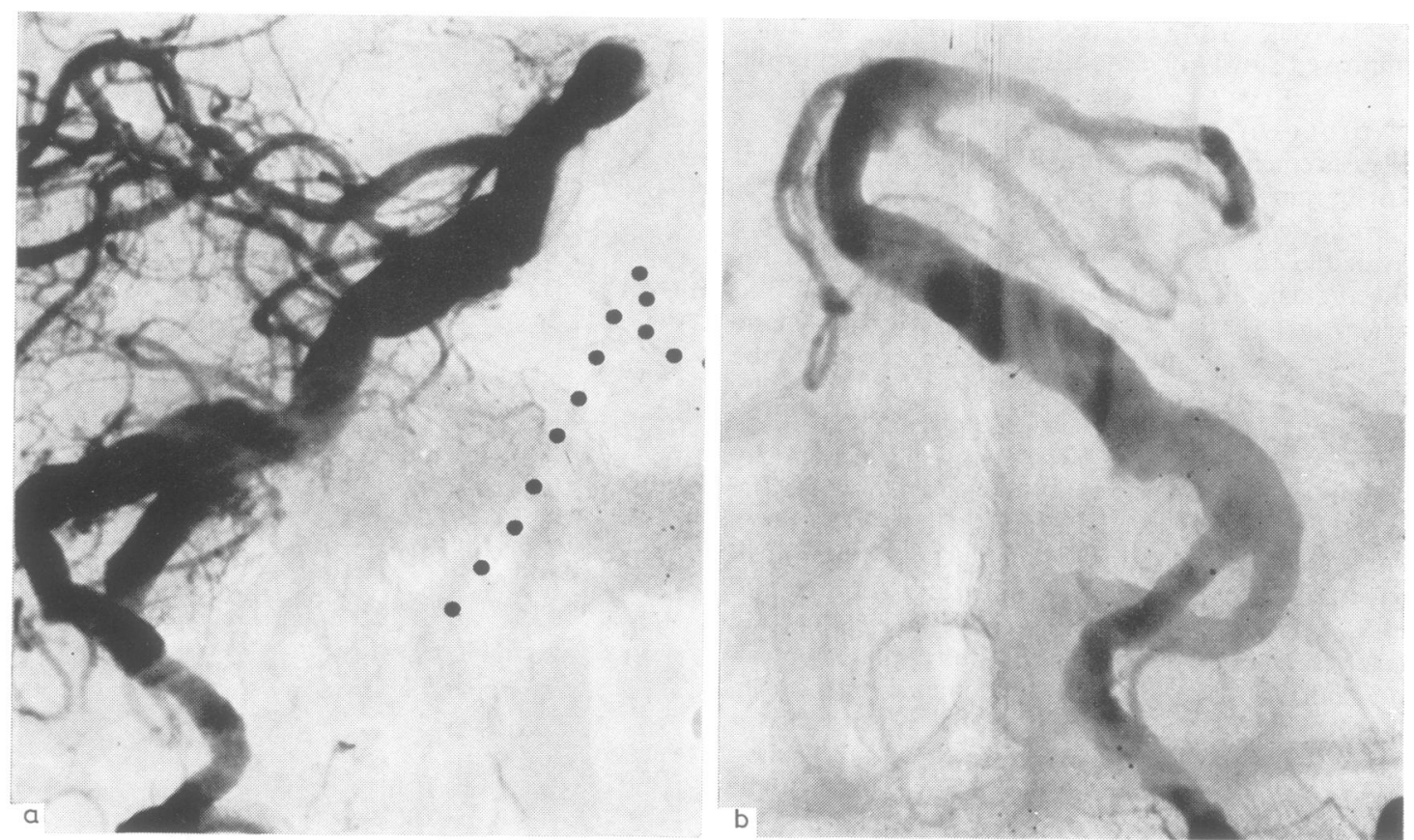

Fig 3 Vertebral angiogram of a 58-year-old male with insidious brain stem deficits, left homonymous hemianopia and temporal lobe epilepsy. (a) lateral (b) AP views. The clivus and sella turcica are indicated by rows of dots. Dilatation, tortuosity and irregularity of the vessels is apparent. The basilar artery measures $7.5 \mathrm{~mm}$ in diameter, the left vertebral $6 \mathrm{~mm}$ and the right vertebral $3.5 \mathrm{~mm}$. Note the marked upward extension of the basilar (22 $\mathrm{mm}$ above the dorsum sella).

three patients, who had presented with acute Horner's syndrome, insidious brain stem deficits and hydrocephalus respectively. In the first case, dilatation and atheromatous changes were evident macroscopically in the right internal carotid artery, the basilar artery and the proximal portion of the other major cerebral arteries. Microscopy of the

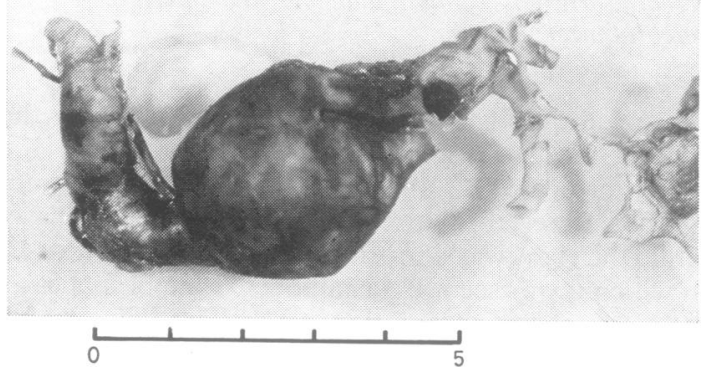

Fig 4 Macroscopic appearances of the ectatic basilar artery in the same patient as in fig 2. Note the marked diffuse enlargement and the aneurysmal formation at the tip. right middle cerebral artery showed atheroma with absence of the normal elastica except in one small area. In the second, the basilar artery was diffusely enlarged, with an aneurysmal dilatation at the vertebrobasilar junction, causing compression of the lateral portion of the medulla and the medial twothirds of the left cerebellum. There was also thrombosis of the distal segment of the left vertebral artery near the origin of the posterior inferior cerebellar artery. Microscopic findings of the ectatic arteries were similar to those in the first. The third case showed considerable atheroma and dilatation of the basilar artery, with aneurysm formation at its tip (fig 4).

\section{Discussion}

The relative rarity of intracranial ectasia (as compared with aortic or brachiocephalic ectasia, which is familiar to the radiologist accustomed to catheterising neck arteries) is borne out by the small number of cases we have been able to assemble from the thousands of angiograms carried out at the National Hospitals since 1959. Nijensohn et $a^{3}$ found only 23 
cases of vertebrobasilar ectasia in all necropsies over 20 years at the Mayo Clinic.

Reports of symptomatic arterial ectasia of the vertebrobasilar system greatly outnumber those of symptomatic involvement of the carotid system. However, in the series of Hultén-Gyllensten et $^{a l}{ }^{6}{ }^{6}$ in which 19 patients were investigated for "various neurological disorders", there were more cases with symptomatic carotid ectasia. The same is true in the present series. It is therefore possible that carotid ectasia, with or without symptoms, is more common than previously supposed. In the series of necropsy findings described by Nijensohn et al, ${ }^{3}$ vertebrobasilar ectasia was often asymptomatic. Only seven of their 23 patients $(30 \%)$ had had neurological symp'oms. It must be stressed however, that the true incidence and distribution of ectasia and the frequency with which it produces symptoms are still uncertain because of the mode of selection of patients and the retrospective nature of the investigations.

Visual problems figured highly in the present series. The patients with carotid ectasia showed unilateral visual failure (5), acute dipolpia (2), homonymous hemianopia (3), and Horner's syndrome (1). Those with vertebrobasilar ectasia had chiasmal compression (1), homonymous hemianopia (1), Horner's syndrome (1), nystagmus (3), and gaze palsies (3). Visual problems in two patients were incidental: one had papilloedema from malignant hypertension and the other suffered chiasmal compression from an anterior communicating aneurysm.

The prognosis in carotid ectasia appears to be considerably better than in vertebrobasilar ectasia. In our series, the mortality in carotid ectasia was lower over a much longer mean follow-up period. The higher death rate in vertebrobasilar ectasia was related to the complications of brain stem compression.

The clinical features of ectasia are probably produced by more than one mechanism, compression and ischaemia being most often incriminated. Their contribution clearly differs in the carotid and vertebrobasilar system. In the latter case, brain stem or cerebellar lesions or both, optic pathway or cranial nerve abnormalities (including facial pain), hydrocephalus and temporal lobe epilepsy could be attributed at least in part to compression, as inferred from the position of ectatic arteries radiologically and pathologically. The lack of correlation between the size of the vertebral and basilar arteries, as demonstrated angiographically, and posterior fossa signs may be due to a disparity between the size of the lumen and the external diameter of the artery, or may indicate that the disposition of the tortuous, looping vessels is more critical.
In contrast, there was only one patient in the present series in whom a focal clinical feature could be related directly to the radiological findings of carotid ectasia : in one case, aneurysmal dilatation of the cervical portion of the internal carotid artery was associated with Horner's syndrome. In all the remaining cases, focal clinical abnormalities were related to thromboembolism or other causes, with the possible exception of the patient with an insidious optic nerve lesion in which compression could not be entirely excluded. Mitts and McQueen, ${ }^{5}$ however, demonstrated at operation in four cases compression of the optic nerve by the ectatic internal carotid artery and collected a further ten examples from the literature. Lee $e t a^{7}$ attributed an atypical chiasmal syndrome to anterior cerebral artery ectasia in six patients, but there was surgical confirmation in only one.

The pathological basis of cerebral ectasia is not well understood. In all of the 23 necropsy cases described by Nijensohn et al, ${ }^{3}$ basilar ectasia was associated with advanced and extensive atheromatous degeneration of the arterial wall. In the present series, many of the clinical features were those associated with generalised arteriosclerosis and the risk factors were similar. Our three post-mortem specimens showed marked atheroma, with, in the two cases examined microscopically, defects in the internal elastic lamina indistinguishable from those seen with atheroma without ectasia. However, in the three necropsy cases of basilar ectasia reported by Greitz and Löftstedt, ${ }^{8}$ no significant atheroma was present in two and microscopic examination in one of these showed "complete absence of elastic substance". It was therefore thought that the enlargement was principally caused by defects in the elastic tissue in the vessels, combined with the effects of arterial hypertension. This observation was also made by Hultén-Gyllensten $e^{2} a^{6}{ }^{6}$ in three out of four necropsy cases. In the post-mortem series of Sacks and Lindenburg, ${ }^{9}$ multiple abrupt gaps and great variation in thickness of the "internal elastic membrane" were present in an unspecified number of the 18 cases examined. They also found incidental ectatic intracranial arteries in a two-year-old child. It would therefore appear that the majority of cases have associated atheroma, but that ectasia can occur in the absence of atheroma. Defects in the internal elastic lamina of the vessel wall are a common feature in either case.

We thank the physicians and surgeons of the National Hospitals for Nervous Diseases for permission to study their patients, and Dr RO Barnard for advice. Dr FE Dische, Dr RF Welch and Dr $\mathrm{K}$ Randall kindly provided necropsy reports and 
pathological material. We also thank Miss J Cox for secretarial help.

\section{References}

${ }^{1}$ Ekbom K, Greitz T, Kugelberg E. Hydrocephalus due to ectasia of the basilar artery. J Neurol Sci $1969 ; 8$ : 465-77.

${ }^{2}$ Boeri R, Passerini A. The megadolichobasilar anomaly. J Neurol Sci 1964; 1:475-84.

${ }^{3}$ Nijensohn DE, Saez RJ, Reagan TJ. Clinical significance of basilar artery aneurysms. Neurology (Minneap) 1974;24:301-5.

${ }^{4}$ Moseley IF, Holland IM. Ectasia of the basilar artery: the breath of the clinical spectrum and the diagnostic value of computed tomography. Neuroradiology 1979;18:83-91.
${ }^{5}$ Mitts MG, McQueen JD. Visual loss associated with fusiform enlargement of the intracranial portion of the internal carotid artery. J Neurosurg 1965;23: 33-7.

${ }^{6}$ Hultén-Gyllensten IL, Löfstedt S, von Reis G. Observations on generalised arteriectasis. Acta Med Scand 1959;163:125-30.

${ }^{7}$ Lee KF, Schatz NJ, Savino PJ. Ischaemic chiasmal syndrome. In: Glaser JS, Smith JL, eds. Neuroophthalmology, Symposium, University of Miami, vol 8. St Louis: Mosby, 1975:115-30.

${ }^{8}$ Greitz T, Löftstedt S. The relationship between the third ventricle and the basilar artery. Acta Radiol (Stockh) 1954;42:85-100.

${ }^{9}$ Sacks JG, Lindenburg R. Dolicho-ectatic intracranial arteries: symptomatology and pathogenesis of arterial elongation and distention. Johns Hopkins Med J 1969;125:95-105. 